Gut, 1984, 25, 931-935

\title{
Loperamide has antisecretory activity in the human jejunum in vivo
}

\author{
S HUGHES, N B HIGGS, AND L A TURNBERG
}

From the Department of Medicine, Hope Hospital, University of Manchester School of Medicine, Salford

SUMMARY We investigated the possibility that loperamide might influence absorption and secretion in the human jejunum in vivo. Using a triple lumen tube perfusion technique in healthy normal volunteers we showed that loperamide did not affect net absorption of water or electrolytes under basal condition. When secretion was induced by prostaglandin $\mathrm{E}_{2}$, however, loperamide significantly reduced that secretion and in three out of six subjects secretion was abolished. Loperamide was effective when it was given either before or after secretion had been initiated. The results lend support to the suggestion that the antidiarrhoeal activities of loperamide may include an antisecretory effect.

The efficacy of loperamide in the treatment of diarrhoea is usually attributed to its actions on intestinal motility. ${ }^{1}$ Its use in secretory, usually infective, types of diarrhoea particularly in children, is controversial as it is commonly assumed that it does not influence intestinal secretion. Paralysis of the gut with pooling of fluid in the intestinal lumen are regarded as potentially dangerous consequences of its use in those types of diarrhoea. ${ }^{2}$ Recent evidence suggests, however, that opiates, including loperamide, influence intestinal salt and water transport and can inhibit secretion in vitro and in vivo. ${ }^{3-5}$

In view of these observations it was important to know whether loperamide has antisecretory activity in man particularly as the theoretical objections to its use in secretory diarrhoeas have not been objectively examined. We report here studies of the influence of loperamide on basal absorption of salt and water in the human jejunum in vivo and on secretion induced by prostaglandin $\mathrm{E}_{2}$.

\section{Methods}

PERFUSION STUDIES

Jejunal perfusion was carried out in 26 healthy volunteers by a triple lumen tube technique as previously described. ${ }^{6}$ After an overnight fast, the tube was swallowed and the infusion site positioned at the ligament of Treitz and checked by radiographic

Address for correspondence: Professor L A Turnberg, Department of Medicine, Hope Hospital, University of Manchester School of Medicine. Eccles Old Road, Salford M6 8HD.

Received for publication 18 November 1983 screening. The mixing segment was $15 \mathrm{~cm}$ long, the test segment $30 \mathrm{~cm}$ and the infusion rate $10 \mathrm{ml} / \mathrm{min}$. In basal studies the equilibration period was 40 minutes and the test period one hour. In experiments with prostaglandin $\mathrm{E}_{2}\left(\mathrm{PGE}_{2}\right)$ the equilibration period was 30 minutes and the test period 40 minutes. During test periods jejunal aspirate from the proximal end of the test segment was collected by suction with a hand held syringe at a rate of $1.5 \mathrm{ml} / \mathrm{min}$. Aspirates from the distal end of the segment were collected by continuous low grade suction. At 15 minute intervals small samples of aspirate were withdrawn and used to measure $\mathrm{pH}$ and $\mathrm{pCO}_{2}$ for the calculation of bicarbonate concentration.

Two perfusion solutions were used, one contained bicarbonate $(\mathrm{Na}, 135 ; \mathrm{K}, 5 ; \mathrm{Cl}, 105 ; \mathrm{HCO} 3,35$; $\mathrm{mmol} / \mathrm{l})$ and the other was bicarbonate-free $(\mathrm{Na}$, $135 ; \mathrm{K}, 5 ; \mathrm{Cl}, 140 ; \mathrm{mmol} / \mathrm{l})$. Both perfusates contained polyethylene glycol 4000 (PEG) $2 \mathrm{gm} / 1$ and ${ }^{14} \mathrm{C}$ PEG $0.5 \mu \mathrm{Ci} / 1$ as a non-absorbable marker. Loperamide solution was administered intraluminally as a bolus of $4 \mathrm{mg}$ or $8 \mathrm{mg}$ followed half an hour later by perfusion with a solution containing loperamide $(3 \mathrm{mg} / \mathrm{l}$ or $6 \mathrm{mg} / \mathrm{l})$. In control periods the same volumes of a placebo solution were given. $\mathrm{PGE}_{2}$ was administered intraluminally by adding it to the perfusate in a final concentration of $5 \times 10^{-6} \mathrm{M}$.

Transit time was assessed by noting the time taken for a $1.5 \mathrm{ml}$ bolus of bromsulphthalein dye (BSP) to pass along the $30 \mathrm{~cm}$ segment as previously described. ${ }^{\top}$ The infusion rate was measured at the beginning and end of the experiment. 
ANALYSIS AND CALCULATIONS

Infused test solutions and aspirates were assayed for

${ }^{14} \mathrm{C} \mathrm{PEG}$ in a liquid scintillation counter (LKB 81000 Scintillation Counter; LKB Wallac). One millilitre samples were added to $10 \mathrm{ml}$ of PCS Scintillation fluid (Amersham, UK) and counted for 10 minutes. Counts per minute were converted to disintegrations per minute from a standard curve using quenched standards. $\mathrm{Na}$ and $\mathrm{K}$ concentrations were measured by flame spectrophotometry (SP6 Spectrophotometer, Pye Unicam) and $\mathrm{Cl}$ concentrations using a chloride meter (Corning Eel). Bicarbonate in the form of $\mathrm{CO}_{2}$ was calculated from the $\mathrm{pCO}_{2}$ and free bicarbonate from the $\mathrm{pH}$ using the HendersonHasselbach equation. Water, electrolyte and bicarbonate movements were calculated by standard equations as previously described. ${ }^{8}$

$\mathrm{PGE}_{2}$ was obtained from Upjohn Ltd, ${ }^{14} \mathrm{C}$ PEG from New England Nuclear, and loperamide from Janssen Pharmaceuticals.

\section{STATISTICAL EVALUATION}

All values are expressed as mean \pm 1 SEM. The statistical significance of differences was determined by paired or unpaired Student's $t$ tests as appropriate and considered significant if $\mathrm{p}<0.05$.

\section{Results}

\section{BASAL STUDIES}

After a one hour control period, four subjects were given a bolus dose of $4 \mathrm{mg}$ loperamide and perfused with the bicarbonate containing test solution and $3 \mathrm{mg} / \mathrm{l}$ loperamide for a one hour test period. The experiment was repeated in a further five subjects using the bicarbonate free perfusate and prolonging the test period to two consecutive hour collections. All subjects absorbed water, $\mathrm{Na}, \mathrm{K}$ and $\mathrm{Cl}$ in the control period and most subjects absorbed $\mathrm{HCO}_{3}$. Subjects perfused with bicarbonate absorbed more water and electrolytes than those perfused with the bicarbonate free solution. In neither instance was absorption influenced by loperamide during the test periods (Table 1). Mean transit time with bicarbonate free perfusate was $7.53( \pm 3 \cdot 34)$ minutes and this was not changed significantly by loperamide $(5 \cdot 85 \pm 2 \cdot 85$ minutes $)$.

\section{INFLUENCE OF LOPERAMIDE ON PGE 2 INDUCED SECRETION}

When 12 subjects were perfused with a test solution containing $5 \times 10^{-6} \mathrm{M} \mathrm{PGE}_{2}$ they all secreted water, $\mathrm{Na}, \mathrm{Cl}$ and $\mathrm{HCO}_{3}$. Nine of the 12 secreted $\mathrm{K}$. Mean transit time was $2 \cdot 66 \pm 0.42$ minutes. After perfusion with $\mathrm{PGE}_{2}$, six of the subjects received a bolus of $4 \mathrm{mg}$ loperamide and were perfused with a test solution containing both $3 \mathrm{mg} / \mathrm{l}$ loperamide and $5 \times 10^{-6} \mathrm{M} \mathrm{PGE}_{2}$. The other six subjects were perfused a second time with $\mathrm{PGE}_{2}$ alone. All six subjects receiving a second perfusion with $\mathrm{PGE}_{2}$ alone secreted less water, $\mathrm{Na} \mathrm{Cl}$ and $\mathrm{HCO}_{3}$ than with their first perfusion (Figure; Table 2). Mean secretion of water fell by $51.7( \pm 8.3) \%, \mathrm{Na}$ by $46 \cdot 4( \pm 7 \cdot 7) \%$ and $\mathrm{Cl}$ by $50 \cdot 1( \pm 8 \cdot 0) \%$. Three of the six subjects given loperamide with the $\mathrm{PGE}_{2}$ reverted to absorption of water and $\mathrm{Cl}$ although control values of absorption were not restored (Figure; Table 2). The mean secretion of water for the six subjects was reduced by $95 \cdot 1( \pm 15 \cdot 2) \%$ compared with their first perfusion with $\mathrm{PGE}_{2}$. Mean Na secretion fell by $73.8( \pm 16.2) \%$ and $\mathrm{Cl}$ by $81.4( \pm 14.9) \%$. The falls in mean water, $\mathrm{Na}$ and $\mathrm{Cl}$ secretion with loperamide plus $\mathrm{PGE}_{2}$ were statistically greater than with $\mathrm{PGE}_{2}$ alone $(\mathrm{p}<0.02)$. Mean transit time was unaffected by loperamide $\left(\mathrm{PGE}_{2}\right.$ alone $2.43 \pm 0.42 \mathrm{~min} ; \mathrm{PGE}_{2}+$ loperamide $3 \cdot 20 \pm 0 \cdot 21 \mathrm{~min})$.

PRETREATMENT WITH LOPERAMIDE

Five subjects were pretreated with an $8 \mathrm{mg}$ bolus of loperamide and then perfused with a solution containing $6 \mathrm{mg} / 1$ loperamide and $\mathrm{PGE}_{2}$ $\left(5 \times 10^{-6} \mathrm{M}\right)$. Under these conditions one subject failed to secrete water and the mean secretion of

Table 1 Influence of loperamide, intraluminally, on absorption of water, $\mathrm{Na}^{+}, \mathrm{K}^{+}, \mathrm{Cl}^{-}$and $\mathrm{HCO}_{3}^{-}$in the human jejunum. $n=4$ for the $\mathrm{HCO}_{3}^{-}$containing perfusate and $n=5$ for $\mathrm{HCO}_{3}^{-}$free perfusate.

\begin{tabular}{|c|c|c|c|c|c|}
\hline & \multicolumn{2}{|c|}{$\mathrm{HCO}_{3}^{-}$containing perfusate } & \multicolumn{3}{|c|}{$\mathrm{HCO}_{3}^{-}$-free perfusate } \\
\hline & Control & Loperamide & Control & $\begin{array}{l}\text { Loperamide } \\
\text { (1st hour) }\end{array}$ & $\begin{array}{l}\text { Loperamide } \\
\text { (2nd hour) }\end{array}$ \\
\hline $\mathrm{H}_{2} \mathrm{O}(\mathrm{ml} / \mathrm{h} / 30 \mathrm{~cm})$ & $120 \cdot 3 \pm 15 \cdot 5$ & $126 \cdot 2 \pm 20 \cdot 2$ & $62 \cdot 2 \pm 11 \cdot 0$ & $78 \cdot 0 \pm 16 \cdot 3$ & $61 \cdot 9 \pm 24 \cdot 5$ \\
\hline $\mathrm{Na}^{+}(\mathrm{mEq} / \mathrm{h} / 30 \mathrm{~cm})$ & $15 \cdot 4 \pm 1 \cdot 8$ & $15 \cdot 16 \pm 2 \cdot 6$ & $7 \cdot 03 \pm 1 \cdot 6$ & $9 \cdot 92 \pm 2 \cdot 0$ & $8 \cdot 18 \pm 3 \cdot 2$ \\
\hline $\mathrm{K}^{+}(\mathrm{mEq} / \mathrm{h} / 30 \mathrm{~cm})$ & $0.75 \pm 0.1$ & $0 \cdot 8 \pm 0 \cdot 1$ & $0 \cdot 38 \pm 0 \cdot 1$ & $0.37 \pm 0.2$ & $0 \cdot 31 \pm 0 \cdot 2$ \\
\hline $\mathrm{Cl}^{-}(\mathrm{mEq} / \mathrm{h} / 30 \mathrm{~cm})$ & $8 \cdot 87 \pm 1 \cdot 2$ & $9 \cdot 89 \pm 2 \cdot 4$ & $6 \cdot 75 \pm 1 \cdot 7$ & $10 \cdot 39 \pm 1 \cdot 9$ & $9 \cdot 16 \pm 3 \cdot 2$ \\
\hline $\mathrm{HCO}_{3}^{-}(\mathrm{mEq} / \mathrm{h} / 30 \mathrm{~cm})$ & $6.91 \pm 2.9$ & $5 \cdot 81 \pm 4 \cdot 3$ & $0 \cdot 24 \pm 0 \cdot 2$ & $0 \cdot 12 \pm 0 \cdot 2$ & $0.05 \pm 0.2$ \\
\hline
\end{tabular}


Table 2 Effect of (a) two consecutive perfusions with $P G E_{2}$ containing fluid and (b) of loperamide given during the second of two consecutive $P G E_{2}$ perfusions on water and electrolyte transport in the human jejunum. -ve sign indicates secretion; $+v e$ sign indicates absorption. Water movement in $\mathrm{ml} / \mathrm{h} / 30 \mathrm{~cm} \pm S E M$ and electrolytes in $\mathrm{mEq} / \mathrm{h} / 30 \mathrm{~cm}$

\begin{tabular}{|c|c|c|c|c|}
\hline & \multicolumn{2}{|l|}{ (a) } & \multicolumn{2}{|l|}{ (b) } \\
\hline & $\begin{array}{l}P G E_{2} \\
\text { (1st perfusion) }\end{array}$ & $\begin{array}{l}P G E_{2} \\
\text { (2nd perfusion) }\end{array}$ & $\begin{array}{l}P G E_{2} \\
\text { (1st perfusion) }\end{array}$ & $\begin{array}{l}P G E_{2}+\text { loperamide } \\
\text { (2nd perfusion) }\end{array}$ \\
\hline $\begin{array}{l}\text { Water } \\
\text { Sodium } \\
\text { Potassium } \\
\text { Chloride } \\
\text { Bicarbonate }\end{array}$ & $\begin{array}{l}-91 \cdot 6 \pm 10.9 \\
-13 \cdot 88 \pm 1 \cdot 1 \\
-0 \cdot 11 \pm 0 \cdot 2 \\
-12 \cdot 42 \pm 0.9 \\
-1 \cdot 73 \pm 0.5\end{array}$ & $\begin{array}{l}-43 \cdot 7 \pm 9 \cdot 1 \\
-7 \cdot 33 \pm 1 \cdot 0 \\
-0 \cdot 7 \pm 0 \cdot 1 \\
-6 \cdot 19 \pm 1 \cdot 0 \\
-0 \cdot 83 \pm 0 \cdot 3\end{array}$ & $\begin{array}{l}-89 \cdot 1 \pm 18 \cdot 9 \\
-14 \cdot 42 \pm 2 \cdot 6 \\
-0 \cdot 36 \pm 0 \cdot 2 \\
-13 \cdot 07 \pm 2 \cdot 8 \\
-1 \cdot 55 \pm 0 \cdot 4\end{array}$ & $\begin{array}{l}-8 \cdot 6 \pm 15 \cdot 6^{*} \\
-3 \cdot 83 \pm 2 \cdot 3^{*} \\
+0 \cdot 13 \pm 0 \cdot 13^{*} \\
-2 \cdot 73 \pm 1 \cdot 9^{*} \\
-0 \cdot 61 \pm 0 \cdot 4\end{array}$ \\
\hline
\end{tabular}

\pm SEM. $\quad{ }^{*} \mathrm{p}<0 \cdot 02 . \quad \mathrm{n}=6$ for each of studies (a) and (b).

water for all five subjects was $36 \cdot 3( \pm 13 \cdot 3) \mathrm{ml} / 30$ $\mathrm{cm} / \mathrm{h}$ compared with a mean secretion of 90.3 $( \pm 10.4) \mathrm{ml} / 30 \mathrm{~cm} / \mathrm{h}$ in the 12 subjects perfused with $\mathrm{PGE}_{2}$ without loperamide pretreatment (Table 3). The difference was statistically significant $(\mathrm{p}<0 \cdot 02)$. Similar trends were seen with $\mathrm{Na}$ and $\mathrm{Cl}$ although these differences were not statistically significant. Mean transit time was not affected by pretreatment

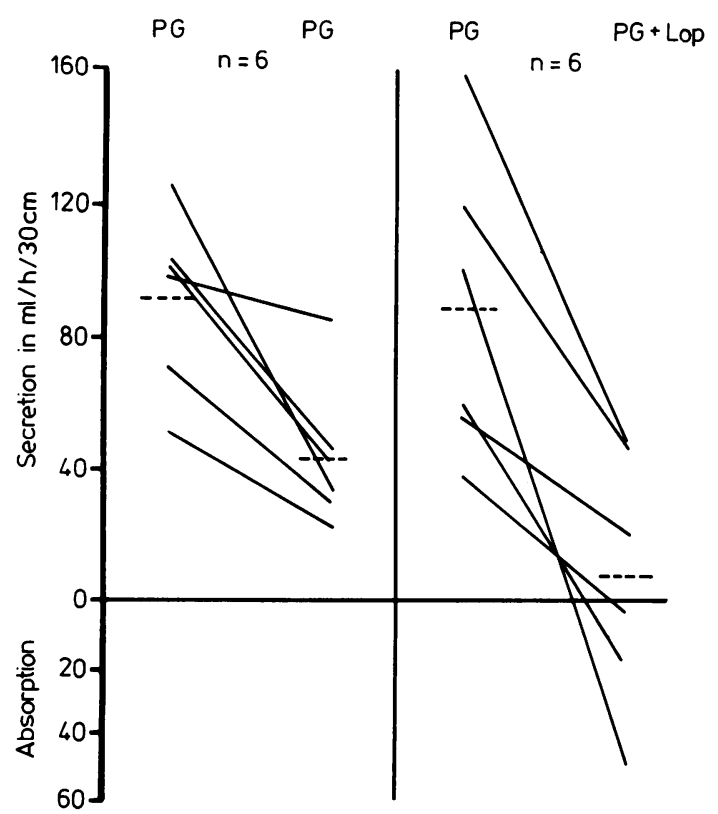

Figure Net water transport in human jejunum in vivo. Secretion induced by prostaglandin $E_{2}(P G)$ is shown above zero line and was significantly less during second of two consecutive perfusion periods (left hand panel). Influence of loperamide, given during second of two $P G E_{2}$ perfusions is shown in right hand panel. Fall in secretion induced by loperamide is significantly greater than that which occurred spontaneously in its absence. with loperamide $\left(\mathrm{PGE}_{2}\right.$ alone $2.43 \pm 0.42 \mathrm{~min}$, pretreated with loperamide $3 \cdot 28 \pm 0 \cdot 4)$.

\section{Discussion}

The well established efficacy of opiates as antidiarrhoeal agents has usually been attributed to their effects on gastrointestinal motility. ${ }^{9}$ Recent studies in animals, however, have indicated that a variety of opiate agonists can influence intestinal secretion. ${ }^{4}{ }^{10}$ Morphine, enkephalins and loperamide have been shown to enhance absorption or inhibit secretion induced by a variety of secretagogues in vitro in ileal mucosa from rabbit or guinea pig. Studies with closed loops of rat intestine in vivo suggest that opiates also have anti-secretory activity in vivo. ${ }^{3}$

In view of the controversy surrounding the use of opiates in secretory diarrhoeas, it was important to investigate the influence of loperamide on the absorption and secretion of salt and water in the human intestine. Loperamide was chosen because of its wide usage as an anti-diarrhoeal agent and because of its apparent safety. ${ }^{11}$

Loperamide did not influence absorption of electrolytes or water when the jejunum was perfused with an isotonic saline solution, or when

Table 3 Effect of pretreatment with loperamide on $P G E_{2}$ induced secretion in the human jejunum. -ve sign indicates secretion; water in $\mathrm{ml} / \mathrm{h} / 30 \mathrm{~cm}$; electrolytes in $\mathrm{mEq} / \mathrm{h} / 30 \mathrm{~cm}$; $P G E_{2}$ alone $n=12$; pretreated with loperamide $n=5$

\begin{tabular}{lll}
\hline & $P G E_{2}$ alone & Loperamide $+P G E_{2}$ \\
\hline Water & $-90.3 \pm 10 \cdot 4$ & $-36 \cdot 3 \pm 13 \cdot 3^{*}$ \\
Sodium & $-14 \cdot 4 \pm 1 \cdot 4$ & $-8 \cdot 08 \pm 1 \cdot 2$ \\
Potassium & $-0 \cdot 23 \pm 0 \cdot 1$ & $-0 \cdot 44 \pm 0.4$ \\
Chloride & $-12 \cdot 75 \pm 1 \cdot 4$ & $-5 \cdot 70 \pm 2 \cdot 3$ \\
Bicarbonate & $-1 \cdot 64 \pm 0 \cdot 3$ & $-1 \cdot 18 \pm 0 \cdot 3$ \\
\hline
\end{tabular}


absorption was stimulated by the presence of bicarbonate in the perfusate. These results resemble the behaviour of rabbit ileal mucosa in vitro in which loperamide did not influence electrolyte transport under basal conditions. ${ }^{4} \mathrm{PGE}_{2}$-induced secretion, however, was inhibited by loperamide. This inhibition, although incomplete, was noted when the loperamide was administered either before or after secretion had been started.

The observation that the effects of prostaglandin alone diminished with time suggests some form of tachyphylaxis. The importance of its demonstration here lies in the necessity to exclude a spontaneous decrease in secretion as a cause of the apparent loperamide effect. Loperamide, however, caused a significantly greater fall in secretion than was observed spontaneously in the second of two prostaglandin perfusion periods. In three of the six subjects given loperamide, secretion was abolished and a small amount of absorption was observed. Furthermore, a comparison of the effect of prostaglandin alone with that of loperamide, given during an initial perfusion with prostaglandin-containing fluid, indicates that the loperamide reduced the response to $\mathrm{PGE}_{2}$.

In these studies $\mathrm{PGE}_{2}$ shortened the transit time measured by the dye-dilution curve technique. It is of interest that loperamide, in this large dose, failed to influence transit time measurements either in the basal state or after $\mathrm{PGE}_{2}$ stimulation. These transit time determinations may not be a good way of detecting motility changes but the results do not suggest that the antidiarrhoeal activity of loperamide is mediated through an effect on motility, at least in the jejunum.

The dose of loperamide used in these experiments was large compared with the usual therapeutic dose. Much larger doses, of up to $1 \mathrm{mg} / \mathrm{kg}$ body weight, however, have been used and shown to be effective in controlling severe secretory diarrhoea in infants. ${ }^{12}$

These results contrast with those of Schiller et al ${ }^{13}$ who studied the effects of codeine in man. Intramuscular codeine reduced stool volume in subjects in whom diarrhoea was induced by intragastric fluid infusions, but did not influence absorption in the gut as a whole or in segments of jejunum, ileum, or colon perfused separately. In addition the reduced absorption of salt and water produced by VIP in the ileum was unaffected by codeine. Transit rates in the jejunum were slowed by codeine. Several reasons may account for the discrepancies between the studies with codeine and loperamide. Firstly, the doses of loperamide we studied would be equivalent to some three to five times more than the dose of codeine used by Schiller et al. Secondly, the loperamide was administered intraluminally, that is directly at the epithelium rather than intramuscularly. Thirdly, different secretagogues were used in the two studies and fourthly it is conceivable that loperamide has different effects from those of codeine. Our failure to influence transit time measurements with high doses of loperamide is of interest in this respect. Finally, the possibility has to be considered that the loperamide reacted in some way with the $\mathrm{PGE}_{2}$ in the lumen and rendered it inactive. We cannot exclude this possibility at present but believe it to be unlikely.

The epithelial effects of opiates are probably mediated through $\delta$ receptors while smooth muscle effects occur via $\mu$ receptors. ${ }^{10}$ It is conceivable that the differences between the effects of codeine and loperamide described above are because of the modest differences in receptor selectivity between these agents. Indeed it might be possible to improve antidiarrhoeal drug design by tailoring them to specific needs, a $\delta$ agonist for secretory types of diarrhoea and a $\mu$ agonist where a motor effect is more desirable.

The antidiarrhoeal actions of loperamide must clearly depend on its effects on the ileum and colon as well as those studied here in the jejunum. Colonic responses may be the most important determinants of clinical responsiveness in many diarrhoeal diseases. The observation, however, that secretion in the jejunum, a site from which many infective, secretory, diarrhoeas arise, can be reduced by loperamide suggests that this drug may have some potential value in the treatment of secretory diarrhoea. The results should encourage the initiation of well controlled clinical trials of its therapeutic efficacy in this type of diarrhoea.

\section{References}

1 Van Neuten JM, Janssen PAJ, Fontaine J. Loperamide (R18553) a novel type of antidiarrhoeal agent. III In vitro studies on the peristaltic reflex and other experiments on isolated tissues. Arzneim Forsch 1974; 24: $1641-5$.

2 von Mühlendahl KE, Bunjes R, Krienke EG. Loperamide-induced ileus. Lancet 1980; 1: 209.

3 Sandhu BK, Triggs JH, Candy DCA, Harries JT. Loperamide: studies on its mechanism of action. Gut 1981; 22: 658-62.

4 Hughes S, Higgs NB, Turnberg LA. Antidiarrhoeal activity of loperamide: studies of its influence on ion transport across rabbit ileal mucosa in vitro. Gut 1982; 23: 944-9.

5 McKay JS, Linaker BD, Higgs NB, Turnberg LA. 
Studies of the anti-secretory activity of morphine in rabbit ileum in vitro. Gastroenterology 1982; 82: 243-7.

6 Fordtran JS, Rector FS Jr, Carter NW. The mechanisms of sodium absorption in the human small intestine. J Clin Invest 1968; 47: 884-900.

7 Morris AI, Turnberg LA. The influence of a parasympathetic agonist and antagonist on human intestinal transport in vivo. Gastroenterology 1980; 79: 861-6.

8 Fordtran JS, Rector FC Jr, Ewton MF, Soter N, Kinney J. Permeability characteristics of the human small intestine. J Clin Invest 1965; 66: 1326-33.

9 Daniel EE, Sutherland WH, Bogoch A. Effects of morphine and other drugs on motilty of the terminal ileum. Gastroenterology 1959; 36: 510-23.
10 Kachur JH, Miller RJ, Field M. Control of guinea pig intestinal electrolyte secretion by a $\delta$ opiate receptor. Proc Natl Acad Sci USA 1980; 77: 2753-6.

11 Verghaegen H, De Cree J, Schuermans V. Loperamide (R18553), a novel type of antidiarrhoeal agent. Efficacy and safety in patients with severe chronic diarrhoea. Arzneim Forsch 1974; 24: 1657-60.

12 Sandhu BK, Tripp TJ, Milla PJ, Harries JT. Loperamide in severe protracted diarrhoea. Arch Dis Child 1983; 58: 39-43.

13 Schiller LR, Davis GR, Santa Ana S, Morawski SG, Fordtran JS. Studies of the mechanism of the antidiarrhoeal effect of codeine. J Clin Invest 1982; 70: 999-1008. 